\title{
Dietary glutamine prevents the loss of intestinal barrier function and attenuates the increase in core body temperature induced by acute heat exposure
}

\author{
Anne D. N. Soares ${ }^{1}$, Kátia A. Costa $^{1}$, Samuel P. Wanner ${ }^{2}$, Rosana G. C. Santos ${ }^{1}$, \\ Simone O. A. Fernandes ${ }^{1}$, Flaviano S. Martins ${ }^{3}$, Jacques R. Nicoli ${ }^{3}$, Cândido C. Coimbra ${ }^{4}$ \\ and Valbert N. Cardoso ${ }^{1 *}$ \\ ${ }^{1}$ Department of Clinical Analysis and Toxicology, School of Pharmacy, Universidade Federal de Minas Gerais, Avenida \\ Antônio Carlos, 6627 Belo Horizonte, MG 31270-901, Brazil \\ ${ }^{2}$ Department of Physical Education, School of Physical Education, Physiotherapy and Occupational Therapy, \\ Universidade Federal de Minas Gerais, Avenida Antônio Carlos, 6627 Belo Horizonte, MG 31270-901, Brazil \\ ${ }^{3}$ Department of Microbiology, Institute of Biological Sciences, Universidade Federal de Minas Gerais, \\ Avenida Antônio Carlos, 6627 Belo Horizonte, MG 31270-901, Brazil \\ ${ }^{4}$ Department of Physiology and Biophysics, Institute of Biological Sciences, Universidade Federal de Minas Gerais, \\ Avenida Antônio Carlos, 6627 Belo Horizonte, MG 31270-901, Brazil
}

(Submitted 7 March 2014 - Final revision received 20 July 2014 - Accepted 24 July 2014 - First published online 17 October 2014)

\section{Abstract}

Dietary glutamine (Gln) supplementation improves intestinal function in several stressful conditions. Therefore, in the present study, the effects of dietary Gln supplementation on the core body temperature ( $\left.T_{\text {core }}\right)$, bacterial translocation (BT) and intestinal permeability of mice subjected to acute heat stress were evaluated. Male Swiss mice ( 4 weeks old) were implanted with an abdominal temperature sensor and randomly assigned to one of the following groups fed isoenergetic and isoproteic diets for $7 \mathrm{~d}$ before the experimental trials: group fed the standard AIN-93G diet and exposed to a high ambient temperature $\left(39^{\circ} \mathrm{C}\right)$ for $2 \mathrm{~h}$ (H-NS); group fed the AIN-93G diet supplemented with L-Gln and exposed to a high temperature (H-Gln); group fed the standard AIN-93G diet and not exposed to a high temperature (control, C-NS). Mice were orally administered diethylenetriaminepentaacetic acid radiolabelled with technetium ( $\left.{ }^{99 \mathrm{~m}} \mathrm{Tc}\right)$ for the assessment of intestinal permeability or ${ }^{99 \mathrm{~m}} \mathrm{Tc}$-Escherichia coli for the assessment of BT. Heat exposure increased $T_{\text {core }}$ (approximately $41^{\circ} \mathrm{C}$ during the experimental trial), intestinal permeability and BT to the blood and liver ( $3 \mathrm{~h}$ after the experimental trial) in mice from the $\mathrm{H}-\mathrm{NS}$ group relative to those from the C-NS group. Dietary Gln supplementation attenuated hyperthermia and prevented the increases in intestinal permeability and BT induced by heat exposure. No correlations were observed between the improvements in gastrointestinal function and the attenuation of hyperthermia by Gln. Our findings indicate that dietary Gln supplementation preserved the integrity of the intestinal barrier and reduced the severity of hyperthermia during heat exposure. The findings also indicate that these Gln-mediated effects occurred through independent mechanisms.

Key words: Bacterial translocation: Hyperthermia: Immunonutrients: Intestinal permeability

Glutamine (Gln) is an amino acid with many important metabolic functions. It serves as a fuel for rapidly dividing cells (particularly lymphocytes and enterocytes) ${ }^{(1,2)}$, induces the expression of heat shock proteins (HSP) ${ }^{(3-6)}$, prevents apoptosis induced by injury ${ }^{(7)}$, has immunoregulatory functions ${ }^{(8,9)}$, and is a key precursor for the intestinal synthesis of glutathione, one of the major antioxidants in the body $^{(3,10,11)}$. Although $\mathrm{Gln}$ is the most abundant amino acid in the bloodstream, under certain conditions of stress, such as trauma, sepsis, major surgery, bone marrow transplantation, and intense chemotherapy and radiotherapy, the physiological requirement for Gln may exceed the capacity for endogenous synthesis such that Gln becomes a conditionally essential amino $\operatorname{acid}^{(3)}$. Thus, dietary Gln supplementation may be a useful strategy to improve the body's response to stressful conditions.

\footnotetext{
Abbreviations: cpm, counts of radioactivity/min.; C-NS group, non-supplemented mice maintained under temperate conditions; DTPA, diethylenetriaminepentaacetic acid; Gln, glutamine; H-Gln group, glutamine-supplemented mice subjected to heat stress; H-NS group, nonsupplemented mice subjected to heat stress; HSP, heat shock proteins; sIgA, secretory IgA.
} 
Recently, our group has reported that Gln therapy is effective at preserving mucosal integrity and preventing increases in intestinal permeability and bacterial translocation (BT) in mice subjected to an experimental model of intestinal obstruction $^{(12)}$. These positive effects of Gln on the intestinal barrier function suggest a potential role for $G \ln$ in the prevention of heat stroke, a life-threatening illness characterised by elevated core body temperatures $\left(T_{\text {core }}\right)$, generally above $40^{\circ} \mathrm{C}$.

Heat stroke events are not rare. According to the US Armed Forces Health Surveillance Center ${ }^{(13)}$, the incidences of heat stroke and 'other heat injury' events among active-duty military recruits in 2011 were 0.25 and 1.82 per 1000 personyears, respectively. A high incidence of heat stroke was also observed during a heat wave in Europe in the summer of 2003, when tens of thousands of people died from heat-related injuries ${ }^{(14)}$. The pathogenesis of heat stroke is complex; marked increases in $T_{\text {core }}$ are associated with blood flow redistribution, which is characterised by cutaneous vasodilation that occurs at the expense of decreased intestinal blood flow ${ }^{(15-18)}$. This splanchnic vasoconstriction may cause ischaemia and limit local vascular heat exchange, thereby promoting bowel tissue hyperthermia. Both intestinal ischaemia and hyperthermia may promote oxidative and nitrosative stresses that stimulate cytoskeletal relaxation, thus contributing to the opening of tight junctions and/or injuries to the epithelium ${ }^{(16,18-21)}$. These morphological and functional changes enhance intestinal permeability ${ }^{(5,19,20)}$, thus facilitating the translocation of bacteria and endotoxins that are normally contained in the intestinal lumen ${ }^{(5,15,19,20,22,23)}$ and subsequently increasing the risk of a systemic inflammatory response syndrome that may culminate in multi-organ system failure and death ${ }^{(16,18)}$.

A previous investigation has already reported Gln-mediated beneficial effects in passively heated animals. Singleton \& Wischmeyer ${ }^{(5)}$ observed that Gln administration decreased gut permeability and plasma endotoxin concentrations and also improved survival following lethal hyperthermia. However, they conducted their study in rats under anaesthesia with ketamine and xylazine, which may represent a confounding factor because deep anaesthesia affects thermoregulation ${ }^{(24)}$. In addition to this methodological issue, Singleton \& Wischmeyer did not address whether oral Gln supplementation could change the ability to maintain $T_{\text {core }}$ during heat exposure. As Gln modulates the release of inflammatory cytokines ${ }^{(25,26)}$ and as systemic inflammation response syndrome is closely associated with thermoregulatory manifestations ${ }^{(27)}$, Gln may also exert beneficial effects in passively heated animals by reducing their thermal strain under extreme environmental conditions.

Heat stroke is a deadly event that affects not only immunocompromised, aged people, but also healthy, young people. Therefore, the present study aimed to assess $T_{\text {core }}$, intestinal permeability and BT to the blood and extra-intestinal organs in unanaesthetised and unrestrained mice exposed to a high ambient temperature. Moreover, because Gln preserves gastrointestinal function under several stressful conditions, another relevant question that was addressed was whether dietary Gln supplementation can alleviate the functional changes in the intestine and the increase in $T_{\text {core }}$ that are induced by a passive heating protocol.

\section{Experimental methods}

\section{Animals and diets}

In total, seventy-eight male Swiss mice ( 4 weeks old) weighing 20.3 (SEM 1.9) g were obtained from the animal care centre at the Faculty of Pharmacy (Federal University of Minas Gerais, Brazil) and were used in all the experiments. Mice were housed in individual cages under controlled light (05.00-19.00 hours) and temperature $\left(24 \cdot 0 \pm 2 \cdot 0^{\circ} \mathrm{C}\right)$ conditions with water and chow provided ad libitum. The experiments were approved by the local Ethics Committee for Animal Experimentation (protocol number: 007/2011) and carried out in compliance with the Guide for the Care and Use of Laboratory Animals published by the Institute of Laboratory Animal Resources.

Mice were surgically implanted with abdominal temperature sensors, allowed to recover for $5 \mathrm{~d}$, and then randomly allocated to three groups: (1) group fed the standard AIN-93G diet and maintained at room temperature during the experimental trials (control and non-supplemented group; C-NS); (2) group fed the standard AIN-93G diet and subjected to a passive heating protocol (hyperthermic and nonsupplemented group; H-NS); (3) group fed the AIN-93G diet supplemented with Gln and subjected to a passive heating protocol (hyperthermic and Gln-supplemented group; H-Gln). The standard AIN-93G diet was originally formulated to support the growth, pregnancy and lactation of rodents by the American Institute of Nutrition ${ }^{(28)}$ and has been used extensively. In the supplemented diet, a portion of casein (equivalent to $4.375 \mathrm{mg} / \mathrm{g}$ ) was replaced with L-Gln (SigmaAldrich). Thus, the standard and Gln-supplemented diets were isoenergetic and isoproteic.

Mice were fed the assigned diets for $7 \mathrm{~d}^{(12,29,30)}$. During this period, water was provided ad libitum and body weight and food intake were measured once and twice a day, respectively. During the light phase of the day, all mice were given access to the AIN-93G diet ad libitum. In contrast, during the dark phase, mice were given access to only $4 \mathrm{~g}$ of food, an amount that they fully consumed on most days. Mice from the $\mathrm{H}-\mathrm{Gln}$ group had access to $4 \mathrm{~g}$ of the supplemented diet, which corresponded to a daily intake of $17.5 \mathrm{mg}$ of Gln or $500 \mathrm{mg} \mathrm{Gln} / \mathrm{kg}$ body weight (i.e. mice had an average body weight of $35 \mathrm{~g}$ on the day of the experimental trials). This dose of Gln was selected based on previous findings that showed decreased BT to the liver, lungs and spleen of mice subjected to intestinal obstruction after the enteral administration of $500 \mathrm{mg} / \mathrm{kg}$ of Gln once a day for $7 \mathrm{~d}^{(29)}$.

After Gln supplementation (or free access to the AIN-93G diet) for $7 \mathrm{~d}$, mice were subjected to the experimental trials: a passive heating protocol or resting under temperate conditions. All experimental trials were performed during the light phase of the day. To achieve the goals of the study, three different sets of animals were used, with mice 
being always allocated to the three groups described earlier (i.e. C-NS, H-NS and H-Gln). The first set of mice ( $n 12$ per group) was used to measure intestinal permeability, whereas the second ( $n 8$ per group) and third ( $n 6$ per group) sets were used to measure BT and secretory IgA (sIgA) concentrations in the intestinal fluid, respectively. The abdominal temperature of all mice subjected to different protocols was recorded during the experimental trials.

\section{Implantation of the abdominal temperature sensor}

A telemetry transmitter was surgically implanted in each mouse for recording $T_{\text {core }}$ (G2 E-Mitter series; Mini Mitter). Mice were weighed and anaesthetised with ketamine ( $60 \mathrm{mg} / \mathrm{kg}$ body weight, intraperitoneally) and xylazine ( $8 \mathrm{mg} / \mathrm{kg}$ body weight, intraperitoneally). During an aseptic procedure, the device was implanted in the abdominal cavity via a midline laparotomy and fixed to the lateral abdominal wall with sutures. Then, the abdominal muscles and skin were sutured in layers ${ }^{(31,32)}$. To prevent surgical hypothermia, the surgery was performed by placing the mice on a pad that was heated to $33^{\circ} \mathrm{C}$.

Mice were allowed to recover from this surgery for $5 \mathrm{~d}$. This period was sufficiently long for the mice to recover and overcome their presurgical body weight (26.2 (SEM 0.7) g postsurgical $v .20 \cdot 4$ (SEM 0.4) g presurgical, $P<0 \cdot 001$; the telemetric probes had an average weight of $1 \cdot 1 \mathrm{~g}$ ). During this recovery period, each mouse was individually housed and maintained under standard environmental conditions and given access to the AIN-93G diet (control) and tap water ad libitum.

\section{Experimental trials}

Mice were weighed and orally administered diethylenetriaminepentaacetic acid (DTPA) radiolabelled with technetium ${ }^{99 \mathrm{~m}} \mathrm{Tc}$ ) for the assessment of intestinal permeability or ${ }^{99 \mathrm{~m}} \mathrm{Tc}-$ Escherichia coli for the assessment of BT. Mice were then allowed to rest for $30 \mathrm{~min}$ in a room with the ambient temperature maintained at $24^{\circ} \mathrm{C}$. Mice from the H-NS and $\mathrm{H}-\mathrm{Gln}$ groups were then transferred from their home cages to an acrylic chamber $(25.5 \mathrm{~cm}$ long $\times 14 \mathrm{~cm}$ wide $\times 13.5 \mathrm{~cm}$ high $)$ that was preheated to $39^{\circ} \mathrm{C}$. An electric fan positioned at one end of the chamber generated an air flow rate of $2 \cdot 0-2.5 \mathrm{~m} / \mathrm{s}$. The environment inside the chamber was heated by placing an electric heater (model AB 1100; Britânia) at the same level $20-30 \mathrm{~cm}$ away from the fan and turned on at $1200 \mathrm{~W}^{(33)}$.

The ambient temperature was set at $39^{\circ} \mathrm{C}$ based on previous findings showing that this environment was sufficiently hot to raise the abdominal temperature of mice above $42^{\circ} \mathrm{C}$ within $4 \mathrm{~h}^{(34)}$. The ambient temperature was measured using a thermocouple (400A; Yellow Springs Instruments). The heat exposure protocol lasted $2 \mathrm{~h}$ or the time required for an animal to exhibit the $T_{\text {core }}$ limit of $42^{\circ} \mathrm{C}$. This $T_{\text {core }}$ value was chosen as a criterion for interrupting the passive heating protocol because it induces autonomic and behavioural responses related to heat stroke ${ }^{(34)}$ without causing mortality in mice ${ }^{(35)}$.

Rather than being exposed to heat, mice from the C-NS group were allowed to move freely in their home cages at an ambient temperature of $24^{\circ} \mathrm{C}$ for $2 \mathrm{~h}$. Food and water were not provided to the mice while they were resting in the cage or during the heat exposure protocol. However, from the end of the heat exposure or control period to the time of killing, they were given free access to water and food again.

\section{Measurements}

Abdominal temperature. Abdominal temperature was measured by telemetry at $30 \mathrm{~s}$ intervals and was considered to represent $T_{\text {core }}$. The radiowave pulses emitted by the temperature sensors were captured by a receiving plate, which was positioned next to the chamber (during the experiments in the hyperthermic groups) or below the home cage of mice (in the C-NS group). The information received by the plate was sent to a data acquisition system (Vital View; Mini Mitter), which converted the frequency values into temperature values.

Telemetry is a technique that allows the measurement of temperature in conscious and freely moving animals without affecting their ability to engage behavioural and autonomic thermoeffectors to deal with environmental challenges. This method eliminates the influence of confounders such as restraint of the animals, stress associated with the insertion of rectal temperature probes, and anaesthesia on the study ${ }^{(35)}$

Intestinal permeability. Intestinal permeability was assessed based on the diffusion of a DTPA solution labelled with ${ }^{99 \mathrm{~m}} \mathrm{Tc}$ that was administered orally. The DTPA probe is large (molecular weight: $500-700 \mathrm{Da}$ ), allowing for the evaluation of intestinal permeability through the paracellular pathway $^{(36)}$

The experimental trials (i.e. heat exposure protocol or resting under temperate conditions for $2 \mathrm{~h}$ ) were carried out 30 min after the administration of $13 \mathrm{MBq}$ of ${ }^{99 \mathrm{~m}}$ Tc-DTPA in a volume of $0 \cdot 1 \mathrm{ml}$. At 3,8 and $18 \mathrm{~h}$ after the experimental trial, groups of six mice were anaesthetised and killed by decapitation. Trunk blood samples $(300 \mu \mathrm{l})$ were collected and placed in appropriate tubes for radioactivity measurement in an automatic gamma counter (Wallac Wizard model 1480; Perkin Elmer).

The percentage of the administered dose present in the blood was calculated using the following equation ${ }^{(30,37-40)}$ :

$$
\% \text { Dose }=(\mathrm{cpm} \text { in blood } / \mathrm{cpm} \text { of standard }) \times 100,
$$

where cpm represents the counts of radioactivity/min.

Bacterial translocation. BT translocation was measured in three more groups of mice ( $n 8$ each). Mice were orally administered $0.1 \mathrm{ml}$ of ${ }^{99 \mathrm{~m}} \mathrm{Tc}-E$. coli ATCC-10 536 (1.8 MBq) containing $10^{8}$ colony-forming units. The radiolabelling of E. coli was performed as described by Diniz et al. ${ }^{(41)}$. The percentage of ${ }^{99 \mathrm{~m}} \mathrm{Tc}$ incorporated into the bacterial cells was determined using the following equation:

$$
\begin{aligned}
\% \text { Labeling }= & (\mathrm{cpm} \text { of precipitate } / \mathrm{cpm} \text { of precipitate } \\
& +\mathrm{cpm} \text { of supernatant } \times 100) .
\end{aligned}
$$

Mice were subjected to the heat exposure protocol or allowed to rest under temperate conditions $30 \mathrm{~min}$ after the 
administration of ${ }^{99 \mathrm{~m}} \mathrm{Tc}-E$. coli. BT was evaluated $3 \mathrm{~h}$ after the heat exposure protocol because within the time points studied this time point corresponded to the period when increased intestinal permeability was observed. Blood, mesenteric lymph nodes, liver, spleen, brain and lungs were collected, weighed and placed into tubes for radioactivity measurement in an automatic gamma counter (Wallac Wizard model 1480; Perkin Elmer). The results are expressed as $\mathrm{cpm}$ relative to the mass of tissue analysed ${ }^{(30,37-40)}$

Immunoglobulin analysis. The small intestines of mice from all groups (C-NS, H-NS and H-Gln; $n 6$ for each group) were removed after killing the mice. The intestinal contents (500 mg) were withdrawn, weighed and resuspended in $2 \mathrm{ml}$ of PBS supplemented with an anti-protease cocktail (1 $\mu \mathrm{m}$-aprotinin, $25 \mu \mathrm{m}$-leupeptin, $1 \mu \mathrm{m}$-pepstatin and $1 \mathrm{~mm}$ phenylmethanesulphonyl fluoride); this anti-protease cocktail was used by Santos et al. ${ }^{(30)}$. The concentrations of SIgA in the intestinal fluid were measured by ELISA using a goat anti-mouse IgA (Sigma Chemical Company) and a horseradish peroxidase-conjugated goat anti-mouse IgA (Sigma), as described previously by Martins et al. ${ }^{(42)}$. The measurements were performed in duplicate. sIgA is an important component of the intestinal protective immunity and acts by reducing the number of epithelium-adherent bacteria, thus limiting BT through the epithelium ${ }^{(43)}$.

\section{Statistical analyses}

The variables studied were tested for normality using the Shapiro-Wilk test. All the variables, except BT data, were normally distributed. The BT data are expressed as medians and analysed using the non-parametric Kruskal-Wallis test. When significance was detected, Mann-Whitney post boc tests were conducted to identify differences among the experimental groups.

Normally distributed data are expressed as means with their standard errors. The abdominal temperature curves were compared between the experimental groups and time points using a two-way ANOVA, with repeated measures only for the time factor. Body weight gain, intestinal permeability, sIgA concentrations and food, energy, protein and nitrogen intakes were compared among the three groups using one-way ANOVA. Tukey's test was used as the post hoc test for variables that had a variation coefficient $<15 \%$ and Duncan's test for variables that had a variation coefficient $>15 \%{ }^{(44)}$. Differences in the preoperative and postoperative body weight were assessed using paired Student's $t$ test (data from the three experimental groups were pooled for this analysis). The role of Gln supplementation in the prevention of the increase of $T_{\text {core }}$ to $42^{\circ} \mathrm{C}$ during the passive heating protocol was assessed using the log-rank test ${ }^{(45)}$.

The AUC of $T_{\text {core }}$ across time points was calculated using trapezoidal integration. The correlation between the thermoregulatory parameters (final abdominal temperature, maximal temperature achieved and area under the temperature curve) and intestinal permeability or sIgA concentrations was assessed using Pearson's coefficient analysis. The correlation between the thermoregulatory parameters and BT was assessed using Spearman's coefficient (non-parametric) analysis.

All analyses were performed using Sigma Plot version 11.0 (Systat Software, Inc.), and $P<0.05$ was defined as statistically significant.

\section{Results}

\section{Body weight gain and food intake}

There were no significant differences in the nutritional parameters evaluated among the three experimental groups ( $P>0.05$ for all nutritional parameters; Table 1). The only exception was the intake of Gln, which was augmented by approximately $17.5 \mathrm{mg} / \mathrm{d}$ in mice from the $\mathrm{H}-\mathrm{Gln}$ group when compared with those from the non-supplemented groups. Mice exhibited an average body weight gain of 7.9 (SEM 0.2) g (pooled data for the three experimental groups) across the $7 \mathrm{~d}$ of treatment with different diets. Their average daily intakes of food, energy and protein were 5.2 (SEM $0 \cdot 1) \mathrm{g}, 81 \cdot 3($ SEM 1.5$) \mathrm{kJ}$ and $1.03($ SEM 0.02$) \mathrm{g}$, respectively.

\section{Core temperature}

Before the experimental trials (at time 0 ), mice exhibited an average $T_{\text {core }}$ that ranged from 37.56 to $37 \cdot 75^{\circ} \mathrm{C}$, and no differences were observed among the three experimental groups (Fig. 1). At an environmental temperature of $24^{\circ} \mathrm{C}$, the $T_{\text {core }}$ of mice from the C-NS group remained stable at

Table 1. Body weight gain and daily chow, energy and protein intakes in the C-NS (nonsupplemented mice maintained under temperate conditions), H-NS (non-supplemented mice subjected to heat stress) and $\mathrm{H}-\mathrm{G}$ In (glutamine-supplemented mice subjected to heat stress) groups during the $7 \mathrm{~d}$ before the experimental trials

(Mean values with their standard errors)

\begin{tabular}{|c|c|c|c|c|c|c|c|}
\hline & \multicolumn{6}{|c|}{ Experimental groups } & \multirow[b]{3}{*}{$P$} \\
\hline & \multicolumn{2}{|c|}{ C-NS } & \multicolumn{2}{|c|}{$\mathrm{H}-\mathrm{NS}$} & \multicolumn{2}{|c|}{$\mathrm{H}-\mathrm{G}$ In } & \\
\hline & Mean & SEM & Mean & SEM & Mean & SEM & \\
\hline Body weight gain (g) & $8 \cdot 6$ & 0.4 & $7 \cdot 8$ & 0.4 & $7 \cdot 4$ & 0.4 & 0.124 \\
\hline Chow intake $(\mathrm{g} / \mathrm{d})$ & $5 \cdot 3$ & 0.2 & $5 \cdot 2$ & 0.2 & 4.9 & 0.2 & 0.286 \\
\hline Energy intake (kJ/d) & 83.5 & $2 \cdot 6$ & $82 \cdot 4$ & $2 \cdot 8$ & $77 \cdot 8$ & 2.5 & 0.286 \\
\hline Protein intake $(\mathrm{g} / \mathrm{d})$ & 1.06 & 0.03 & 1.05 & 0.04 & 0.99 & 0.03 & 0.286 \\
\hline
\end{tabular}




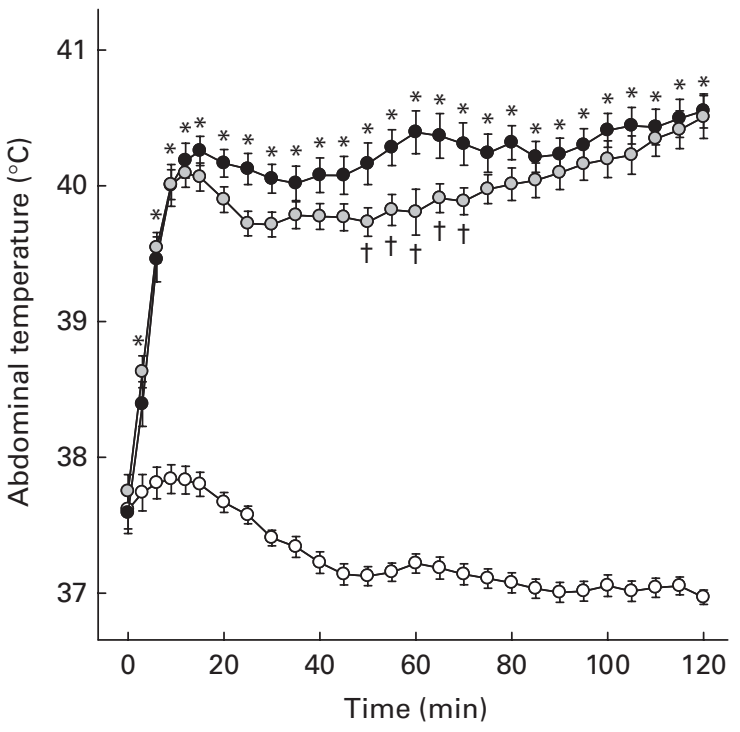

Fig. 1. Abdominal temperature of mice during the experimental trials. C-NS group, non-supplemented mice maintained under temperate conditions $(-\mathrm{O})$; H-NS group, non-supplemented mice subjected to heat stress (- - ); and $\mathrm{H}-$ GIn group, glutamine-supplemented mice subjected to heat stress (-o). Values are means (n 26 per group), with their standard errors represented by vertical bars. * Mean values for the $\mathrm{H}-\mathrm{NS}$ and the $\mathrm{H}-\mathrm{G}$ In group were significantly different that of the $\mathrm{C}$-NS group $(P<0.001)$. $†$ Mean value was significantly different from that of the H-NS group $(P<0.05)$.

approximately $37 \cdot 5^{\circ} \mathrm{C}$ for $20 \mathrm{~min}$ and then gradually decreased to $37 \cdot 0^{\circ} \mathrm{C}$, a value that was sustained until the end of the recording period. The fact that $T_{\text {core }}$ decreased in mice from the C-NS group as the experiments progressed indicates that the trials were initiated when the mice were still under the effects of stress hyperthermia induced by the handling and oral administration procedures.

The heat-exposed mice (i.e. the H-NS and H-Gln groups) exhibited a steep increase in $T_{\text {core }}$ because of the exposure to an uncompensated environmental heat load (Fig. 1). Exposure to a high ambient temperature $\left(39^{\circ} \mathrm{C}\right)$ significantly increased the $T_{\text {core }}$ of mice from the H-NS group relative to those from the C-NS group from the 3rd min to the end of the heat exposure protocol (40.90 (SEM 0.17) v. 37.02 (SEM $0 \cdot 07)^{\circ} \mathrm{C}$ at the end; $\left.P<0.001\right)$. Heat exposure also increased the $T_{\text {core }}$ of mice from the $\mathrm{H}-\mathrm{Gln}$ group relative to those from the C-NS group; however, Gln-supplemented mice exhibited attenuation of hyperthermia compared with nonsupplemented mice from the 49th to the 70th min of heating (39.86 (SEM 0.11) v. $40.33(\operatorname{sem~} 0 \cdot 15)^{\circ} \mathrm{C}$ at the 70 th min; $P<0 \cdot 05$; Fig. 1).

This Gln-induced protective thermoregulatory effect was also evident from the analysis of the percentage of mice in which the $T_{\text {core }}$ limit of $42^{\circ} \mathrm{C}$ was reached during the passive heating protocol $(P<0.05 ;$ log-rank test $)$. Of the twenty-six mice from the H-NS group, six (23\%) exhibited a $T_{\text {core }}$ of $42^{\circ} \mathrm{C}$ before the end of the $2 \mathrm{~h}$ heat exposure protocol (Fig. 2). In contrast, this temperature limit was reached in only one mouse from the H-Gln group (4\%). It is worth noting that during the passive heating protocol, one mouse from the H-NS group died with a $T_{\text {core }}$ value of $41.5^{\circ} \mathrm{C}$ after being exposed to heat for $100 \mathrm{~min}$ (this mouse was excluded from all analyses). No mice from the H-Gln group died during the experimental trials.

\section{Intestinal permeability}

Mice from the C-NS group exhibited a physiological range of intestinal permeability values at 3, 6 and $18 \mathrm{~h}$ after the experimental trial (Fig. 3). At $3 \mathrm{~h}$ after the heat exposure protocol, mice from the H-NS group exhibited an increased intestinal permeability that was approximately eleven to twelve times higher than that of mice from the C-NS group (Fig. 3); however, this augmented intestinal permeability was transient, and no differences were observed between these two groups at 6 and $18 \mathrm{~h}$ after the experimental trial. Dietary Gln supplementation prevented the increase in intestinal permeability that was observed in mice from the H-NS group at $3 \mathrm{~h}$ after the heat exposure protocol. In fact, the uptake of ${ }^{99 \mathrm{~m}}$ Tc-DTPA in the blood samples of mice from the H-Gln group was similar to that in mice from the C-NS group at every time point studied.

\section{Bacterial translocation}

Mice from the C-NS group exhibited a physiological level of BT to the blood and all organs at $3 \mathrm{~h}$ after the experimental trial (which corresponded to the time point when increased intestinal permeability caused by passive heating was observed; Table 2). Heat exposure increased BT, as demonstrated by a significantly increased uptake of ${ }^{99 \mathrm{~m}} \mathrm{Tc}-E$. coli by the blood and liver $(P<0.05)$ and a tendency for higher uptake by the lungs $(P=0.064)$ in mice from the H-NS group

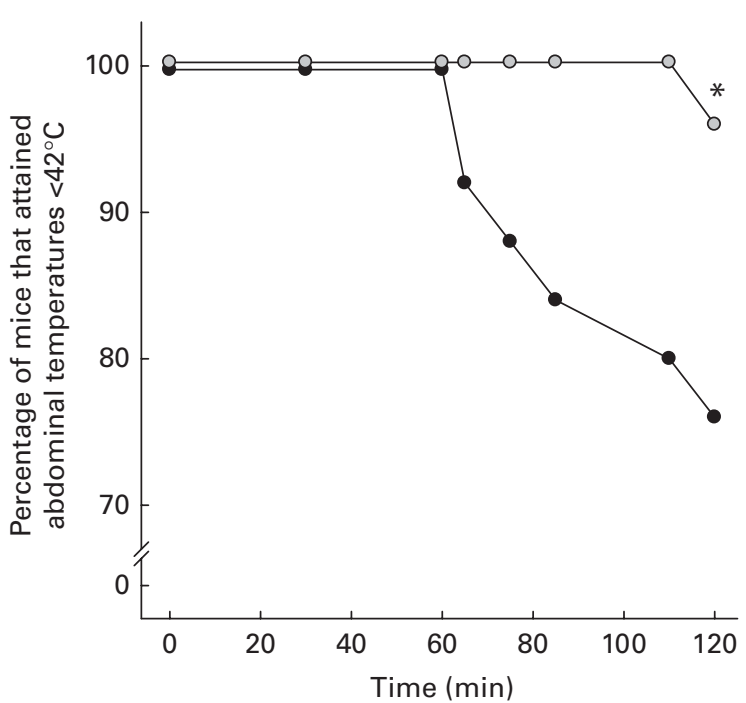

Fig. 2. Percentage of mice that did not attain the abdominal temperature limit of $42^{\circ} \mathrm{C}$ at different time points during the passive heating protocol ( $n 26$ per group). H-NS group, non-supplemented mice subjected to heat stress $(--)$, and $\mathrm{H}-\mathrm{Gln}$ group, glutamine-supplemented mice subjected to heat stress (-O-). * Percentage of mice along the whole experimental trial was significantly different from that of the H-NS group $(P<0.05)$. 


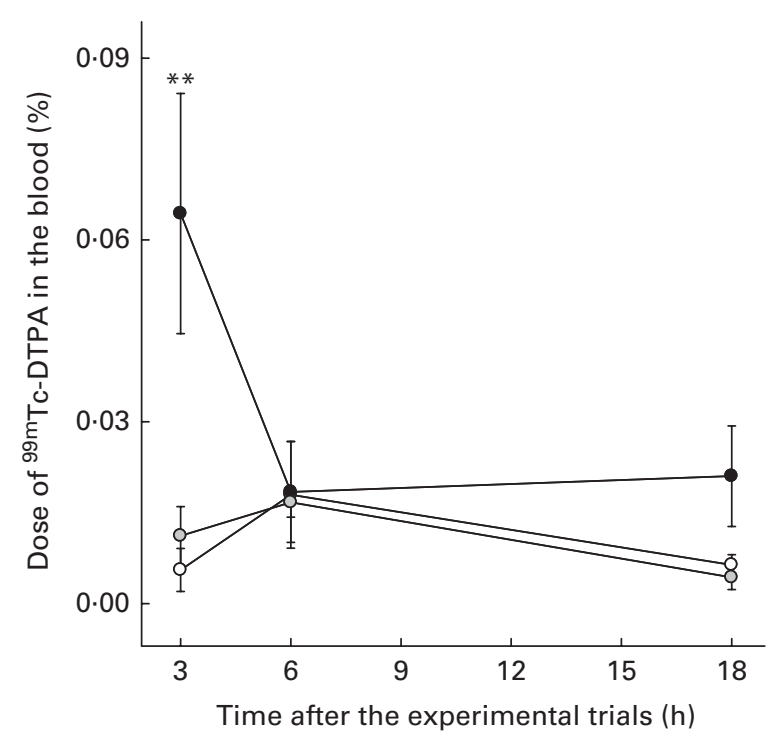

Fig. 3. Intestinal permeability of mice at 3,6 and $18 \mathrm{~h}$ after the experimental trials. C-NS group, non-supplemented mice maintained under temperate conditions (-O-); H-NS group, non-supplemented mice subjected to heat stress (-๑); and H-Gln group, glutamine-supplemented mice subjected to heat stress (-o-). Values are means (n 12 per group; four for each time point), with their standard errors represented by vertical bars. ${ }^{\star \star}$ Mean value was significantly different from those of the C-NS and H-Gln groups $(P<0.01)$. DTPA, diethylenetriaminepentaacetic acid; \% dose $=((\mathrm{cpm}$ in blood $\times 100) /$ $\mathrm{cpm}$ of administered dose), where $\mathrm{cpm}=$ counts $/ \mathrm{min}$.

compared with those from the C-NS group (Table 2). Dietary Gln supplementation prevented the hyperthermia-induced BT to the blood, liver and lungs; the uptake of ${ }^{99 \mathrm{~m}} \mathrm{Tc}-E$. coli in mice from the H-Gln group was lower than that in mice from the H-NS group $(P<0.05)$ and did not differ from that in mice from the C-NS group. No differences were observed in the uptake of ${ }^{99 \mathrm{~m}} \mathrm{Tc}-E$. coli by the mesenteric lymph nodes, spleen and brain among the three experimental groups.

\section{Secretory IgA concentrations in the intestinal fluid}

At $3 \mathrm{~h}$ after the experimental trial, no differences were observed in sIgA concentrations among the three experimental groups $(P=0 \cdot 20 ;$ Fig. 4$)$.

\section{Correlation analyses}

Correlation analyses were performed to determine whether the beneficial effects of Gln supplementation on intestinal function were associated with Gln-mediated changes in thermoregulation. Intestinal permeability, BT and sIgA concentrations were found to be not significantly associated with any of the evaluated thermoregulatory parameters (i.e. the $T_{\text {core }}$ after $2 \mathrm{~h}$ of heat exposure, the highest $T_{\text {core }}$ value recorded or the area under the $T_{\text {core }}$ curve during the passive heating protocol; Table 3). The only exception was the positive and significant correlation between sIgA concentrations and the highest $T_{\text {core }}$ attained during heat exposure $(r$ 0.63; $P<0.05)$.

\section{Discussion}

The results of the present study demonstrate that the nonsupplemented vigil mice subjected to acute heat stress attained high $T_{\text {core }}$ values that were sustained above $40^{\circ} \mathrm{C}$ for approximately $100 \mathrm{~min}$ (Fig. 1). This marked hyperthermia was associated with increased intestinal permeability (Fig. 3) and BT to the blood and liver (Table 2). The results also demonstrate that dietary Gln supplementation improved the intestinal barrier function, thereby preventing the increase in intestinal permeability and limiting the BT induced by the passive heating protocol. Another interesting finding was that dietary Gln supplementation reduced the magnitude of passive hyperthermia (Fig. 1) and reduced the risk of reaching the $T_{\text {core }}$ limit of $42^{\circ} \mathrm{C}$ (Fig. 2).

All the experimental groups were fed isoenergetic and isonitrogenous diets and exhibited similar food intake and body weight gain (Table 1). These data indicate that mice tolerated the supplemented diet well, despite the possibility that the addition of Gln, a virtually tasteless powder ${ }^{(46)}$, may have changed the taste of the diet. This possibility is an important concern because malnutrition induces $\mathrm{BT}^{(47)}$ and decreases $T_{\text {core }}{ }^{(48)}$. These data also indicate that the beneficial effects observed in the supplemented groups can be exclusively attributed to the actions of Gln.

Increased intestinal permeability was transiently observed in the passively heated animals; when compared with control

Table 2. Bacterial translocation (counts of radioactivity per minute $(\mathrm{cpm}) / \mathrm{g}$ ) to the blood and extra-intestinal organs in the C-NS (non-supplemented mice maintained under temperate conditions), H-NS (non-supplemented mice subjected to heat stress) and H-Gln (glutamine-supplemented mice subjected to heat stress) groups* (Median and 25th and 75th interquartile ranges (IQR))

\begin{tabular}{|c|c|c|c|c|c|c|c|}
\hline \multirow[b]{2}{*}{ Organ/blood } & \multicolumn{2}{|c|}{ C-NS } & \multicolumn{2}{|c|}{$\mathrm{H}-\mathrm{NS}$} & \multicolumn{2}{|c|}{ H-Gln } & \multirow[b]{2}{*}{$P$} \\
\hline & Median & IQR & Median & IQR & Median & IQR & \\
\hline MLN & 650 & $153-1120$ & 733 & $99-4128$ & 670 & $528-1346$ & 0.925 \\
\hline Blood & $558^{a}$ & $390-815$ & $1675^{b}$ & $713-2860$ & $724^{a}$ & $537-1009$ & 0.020 \\
\hline Brain & 602 & $261-706$ & 641 & $115-1563$ & 307 & $165-677$ & 0.821 \\
\hline Liver & $2584^{a}$ & $1853-3150$ & $9274^{\mathrm{b}}$ & $4656-10897$ & $4158^{\mathrm{a}}$ & $1881-5733$ & 0.013 \\
\hline Lungs & 640 & $587-902$ & 3868 & $627-4929$ & 1931 & $768-2163$ & 0.064 \\
\hline Spleen & 294 & $191-479$ & 986 & $110-1858$ & 587 & $221-1531$ & 0.471 \\
\hline
\end{tabular}

MLN, mesenteric lymph nodes.

${ }^{\mathrm{a}, \mathrm{b}}$ Median values with unlike superscript letters were significantly different between the experimental groups $(P<0.05)$.

* Simultaneous comparison was performed among the different experimental groups ( $n 8$ per group). 


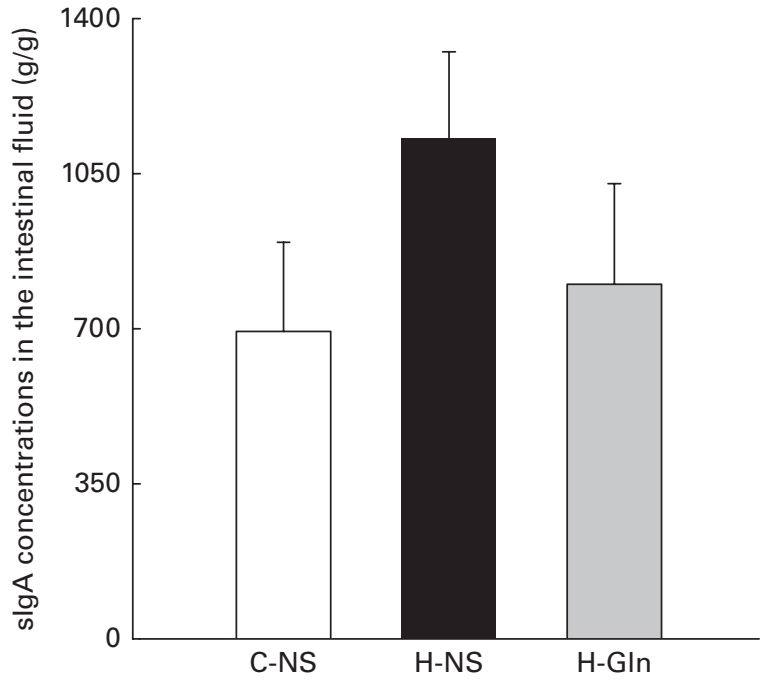

Fig. 4. Secretory $\lg A(\operatorname{sg} A)$ concentrations in the intestinal fluid of mice at $3 \mathrm{~h}$ after the experimental trials. C-NS group, non-supplemented mice maintained under temperate conditions ( $\square$ ); H-NS group, non-supplemented mice subjected to heat stress ( $\square$ ); and H-GIn group, glutamine-supplemented mice subjected to heat stress $(\square)$. Values are means (n 6 per group), with their standard errors represented by vertical bars.

animals (C-NS), these hyperthermic animals (H-NS) exhibited higher intestinal permeability at $3 \mathrm{~h}$ after the experimental trial, but not after 6 and $18 \mathrm{~h}$ (Fig. 3). This increased intestinal permeability is in agreement with the results of previous studies in which anaesthetised animals were subjected to different passive heating protocols ${ }^{(5,15,19,21)}$ and with the demonstration of rapid repair of the intestinal epithelium after hyperthermia-induced injury ${ }^{(49)}$. Moreover, as we measured the radioactivity levels of ${ }^{99 \mathrm{~m}} \mathrm{Tc}$-DTPA in the blood to determine intestinal permeability, we conclude that the increased permeation observed at $3 \mathrm{~h}$ most probably occurred through the paracellular pathway.

The results of the present study do not exclude the possibility that intestinal permeability may have been even more pronounced in the period between the end of exposure and before the $3 \mathrm{~h}$ recovery period. This hypothesis is supported by other studies showing significant increases in intestinal permeability shortly after passive hyperthermia ${ }^{(15,19,21)}$.

There was no significant difference in sIgA concentrations in the intestinal fluid among the experimental groups (Fig. 4), suggesting that the passive heating protocol did not change the number of immunocompetent cells in the lamina propria and the local production of cytokines involved in IgA synthesis ${ }^{(50,51)}$. The concentrations of sIgA were positively correlated with the highest $T_{\text {core }}$ attained during the heat exposure protocol (Table 3) and tended to be higher in mice from the H-NS group than in those from the C-NS group (Fig. 4). These observations suggest a physiological association between the intestinal concentrations of $\operatorname{sigA}$ and the magnitude of hyperthermia, which should be investigated further. Nevertheless, the positive correlation between the concentrations of SIgA and the magnitude of hyperthermia suggests that the intestinal immune system is acting properly to restrain BT at physiological levels. Previous evidence suggests that the increased intestinal permeability caused by hyperthermia could be attributed to an injury to the epithelial cell lining and/or opening of epithelial tight junctions ${ }^{(16,18-20)}$.

Mice from the C-NS group exhibited a low level of BT to the blood and all evaluated extra-intestinal organs, confirming that BT is a physiological process essential for the maturation and maintenance of a competent gastrointestinal immune system $^{(43)}$. In contrast, $3 \mathrm{~h}$ after exposure to acute heat stress (exactly at the time when augmented intestinal permeability was observed), mice from the H-NS group exhibited an increased uptake of ${ }^{99 \mathrm{~m}} \mathrm{Tc}-E$. coli in the blood and liver relative to those from the C-NS group. This finding is in agreement with previous reports showing that impaired bowel function increases intestinal permeability, which may facilitate $\mathrm{BT}^{(43,52,53)}$. It is likely that the bacteria and their products translocated via the portal circulation to the blood and liver in the heat-stressed mice, corroborating recent observations in mice that performed prolonged physical exercise in the heat and also demonstrated increased bacterial levels in the blood and liver ${ }^{(31)}$. According to Wiest \& Rath ${ }^{(43)}$, bacteria may translocate from the gastrointestinal tract through different routes: (1) via blood vessels to reach the portal system; (2) by direct transmural migration across the intestinal wall; (3) by retrograde migration to the lungs; (4) by lymphatic migration via Peyer's patches to reach mesenteric lymph nodes, followed by movement from the thoracic duct into the left subclavian vein to reach the right side of the heart and then enter the pulmonary circulation. The preferential route for BT probably varies according to the magnitude of the inflammatory insult ${ }^{(54)}$. Our recent findings suggest that BT associated with hyperthermic states (induced by passive heating or physical exercise) occurs preferentially through the portal circulation. In addition, the contribution of a translocation pathway that involves the lungs cannot be excluded

Table 3. Correlations between thermoregulatory parameters and intestinal permeability, bacterial translocation and secretory $\lg A(\operatorname{sgA})$ concentrations in the $\mathrm{H}$-NS group (non-supplemented mice subjected to heat stress) and the H-Gln group (glutamine-supplemented mice subjected to heat stress)

\begin{tabular}{lcc}
\hline Correlations & Coefficient & $P$ \\
\hline Intestinal permeability & & \\
$\quad$ Final core temperature $\left({ }^{\circ} \mathrm{C}\right)$ & 0.33 & 0.422 \\
$\quad$ Maximal core temperature $\left({ }^{\circ} \mathrm{C}\right)$ & 0.32 & 0.434 \\
$\quad$ Area under the temperature curve $\left({ }^{\circ} \mathrm{C} \times \mathrm{min}\right)$ & 0.09 & 0.830 \\
Bacterial translocation to the blood & & \\
$\quad$ Final core temperature $\left({ }^{\circ} \mathrm{C}\right)$ & 0.09 & 0.730 \\
Maximal core temperature $\left({ }^{\circ} \mathrm{C}\right)$ & 0.00 & 0.969 \\
Area under the temperature curve $\left({ }^{\circ} \mathrm{C} \times \min \right)$ & 0.19 & 0.469 \\
Bacterial translocation to the liver & & \\
$\quad$ Final core temperature $\left({ }^{\circ} \mathrm{C}\right)$ & -0.02 & 0.926 \\
Maximal core temperature $\left({ }^{\circ} \mathrm{C}\right)$ & -0.05 & 0.848 \\
Area under the temperature curve $\left({ }^{\circ} \mathrm{C} \times \min \right)$ & -0.26 & 0.331 \\
Intestinal slgA & & \\
$\quad$ Final core temperature $\left({ }^{\circ} \mathrm{C}\right)$ & 0.52 & 0.082 \\
Maximal core temperature $\left({ }^{\circ} \mathrm{C}\right)$ & 0.63 & 0.028 \\
Area under the temperature curve $\left({ }^{\circ} \mathrm{C} \times \min \right)$ & 0.48 & 0.115 \\
\hline
\end{tabular}

* Pearson's coefficient $(r)$ was used for correlations between thermoregulatory parameters and intestinal permeability or slgA concentrations, whereas Spearman's coefficient $\left(r_{\mathrm{s}}\right)$ was used for correlations between thermoregulatory parameters and bacterial translocation. 
because the bacterial content of the lungs of mice from the H-NS group tended to be higher than that of mice from the $\mathrm{C}-\mathrm{NS}$ and $\mathrm{H}-\mathrm{Gln}$ groups. We also measured the bacterial content in the brain because hyperthermia may augment the permeation of the blood-brain barrier ${ }^{(18)}$. However, the BT to the brain was not affected by acute heat stress or dietary Gln supplementation (Table 2).

Notably, liver failure is frequently associated with heat stroke ${ }^{(18)}$. In the present study, mice tolerated the heat stress well, and no deaths were observed in mice in which intestinal permeability was measured $18 \mathrm{~h}$ after the experimental trial. In fact, the impairment of gastrointestinal function was shortlived compared with that observed in more severe heat stress protocols ${ }^{(5)}$, in which anaesthetised rats were heated until reaching a rectal temperature of $42^{\circ} \mathrm{C}$ (a level of hyperthermia that was maintained for $30 \mathrm{~min}$ ) and consequently exhibited increased permeability 6 and $24 \mathrm{~h}$ after the heat exposure protocol had ceased. Therefore, it is likely that the heat exposure protocol used in the present study did not cause major dysfunctions in Küpffer cells. This assumption is supported by the finding that BT to the other extra-intestinal organs was not increased above the physiological levels, suggesting that the liver efficiently acted as a scavenger of bacteria and their products ${ }^{(43)}$. Similarly, Hall et $a l .^{(15)}$ demonstrated higher concentrations of bacterial endotoxin in the portal venous blood, but not in the arterial blood, of anaesthetised rats that were subjected to an increase in colonic temperature from $37 \cdot 0$ to $41 \cdot 5^{\circ} \mathrm{C}$ via exposure to an ambient temperature of $40^{\circ} \mathrm{C}$, relative to non-stressed animals.

The attenuated increase in $T_{\text {core }}$ in Gln-supplemented mice that were passively exposed to heat is a novel finding of the present study (Fig. 1). Our findings are not corroborated by previous observations in humans experiencing endotoxaemia, in whom the magnitude of the febrile response was not influenced by intravascular infusion of $G \ln ^{(55)}$. Similarly, a recent investigation subjecting human subjects to treadmill running under a high ambient temperature did not reveal any Gln-induced change in $T_{\text {core }}$ at the end of the exercise ${ }^{(6)}$. We speculate that this thermoregulatory effect mediated by Gln may be influenced by the dose, frequency and route of Gln administration or may be specific to certain stressful conditions or animal species.

Facilitated heat loss is a physiological response that could explain the attenuated hyperthermia observed in supplemented animals. However, an increase in cutaneous vasodilation mediated by Gln is unlikely to account for the lower $T_{\text {core }}$ because the temperature gradient between the skin and environment is narrow (if not reversed) at an ambient temperature of $39^{\circ} \mathrm{C}$; this low gradient hampers dry heat loss from the body. Whether dietary Gln supplementation facilitates evaporative heat loss or behavioural thermoregulation remains to be determined. Another potential explanation for the attenuated hyperthermia is the diminished release of inflammatory cytokines and eicosanoids that provoke fever, consistent with previous findings showing that Gln decreases the plasma and tissue concentrations of TNF- $\alpha$, IL- 6 and $\mathrm{PGE}_{2}^{(25,26)}$. Finally, the reduced $T_{\text {core }}$ may be the result of a Gln-induced reduction in intestinal blood flow, limiting the delivery of warmed blood from the hot skin to the gastrointestinal system and thereby attenuating the increase in abdominal temperature. The latter hypothesis is supported by Matheson et $a l .{ }^{(56)}$, who showed that enteral Gln supplementation impairs nutrient-driven absorptive hyperaemia in the colon, pancreas, spleen and throughout the small intestine.

The protective effect exerted by Gln on the intestinal barrier function was independent of the attenuation of hyperthermia (Table 3). The beneficial effects of dietary Gln enrichment on gastrointestinal function have already been reported in rodents subjected to different stressful conditions that are not necessarily associated with hyperthermia, such as intestinal obstruction ${ }^{(12,30)}$ and burns ${ }^{(9)}$. Under these experimental conditions, Gln exerts beneficial effects through several mechanisms, including intestinal tropism ${ }^{(57)}$, inhibition of apoptosis ${ }^{(7)}$, stimulation of the Th1 inflammatory response ${ }^{(8)}$, reinforcement of the immune system against bacteria and endotoxins $^{(9)}$, preservation of glutathione ${ }^{(11)}$ and increased expression of $\mathrm{HSP}^{(3,5)}$. In particular, HSP are involved in the most basic mechanisms of cellular protection against stressful conditions ${ }^{(58)}$. Treatment with Gln has been shown to up-regulate the expression of HSP genes in hyperthermic animals $^{(3,5)}$, similarly to the HSP expression promoted by a heat acclimation protocol ${ }^{(59)}$. Moreover, animals that have undergone genetic knockout of key HSP pathway mediators are not protected against sepsis and lung injury by Gln administration $^{(25)}$. Recently, Zuhl et al. ${ }^{(6)}$ have shown that in vitro Gln supplementation increases the concentrations of HSP70 and heat shock factor-1 (the transcription factor that regulates HSP70) in response to heat stress; moreover, the combined effect of Gln and heat increased the expression of occludin. Similarly, Beutheu et al. ${ }^{(60)}$ demonstrated that Gln prevented changes in the concentrations of occludin, claudin-1 and zonula occludens-1 during chemotherapy-induced mucositis in rats. Together, these findings suggest that the Gln-mediated intestinal protection may also be due to the modulation of the tight-junction proteins.

In conclusion, acute exposure to heat induced marked hyperthermia, increased intestinal permeability and increased BT that most probably occurred via the portal circulation. Dietary Gln supplementation decreased the magnitude of hyperthermia and prevented the increases in BT and intestinal permeability caused by the passive heating protocol. Taking these findings into account, we suggest that Gln supplementation may be an important nutritional strategy for preventing severe hyperthermia and heat-related disorders.

\section{Acknowledgements}

The authors are grateful to the following sources for providing financial support: Pró-Reitoria de Pesquisa da Universidade Federal de Minas Gerais (PRPq/UFMG); CNPq (the National Council of Technological and Scientific Development); CAPES (the Coordination for the Improvement of Higher Education Personnel); FAPEMIG (the Minas Gerais State Foundation for Research Support). The funding agencies had no role in the design and analysis of the study or in the writing of this article. 
The authors' contributions are as follows: A. D. N. S., K. A. C., S. P. W., C. C. C. and V. N. C. designed the study; A. D. N. S., K. A. C., S. P. W., R. G. C. S. and F. S. M. conducted the study; A. D. N. S., S. P. W., S. O. A. F., J. R. N., C. C. C. and V. N. C. analysed the data; A. D. N. S., S. P. W. and V. N. C. wrote the article; V. N. C. had primary responsibility for the final content. All authors read and approved the final version of the manuscript.

None of the authors has any conflicts of interest to declare.

\section{References}

1. Kew S, Wells SM, Yaqoob P, et al. (1999) Dietary glutamine enhances murine T-lymphocyte responsiveness. I Nutr 129, 1524-1531.

2. Boelens PG, Nijveldt RJ, Houdijk AP, et al. (2001) Glutamine alimentation in catabolic state. J Nutr 131, 2569S-2577S.

3. Wischmeyer PE, Musch MW, Madonna MB, et al. (1997) Glutamine protects intestinal epithelial cells: role of inducible HSP70. Am J Physiol 272, G879-G884.

4. Chow A \& Zhang R (1998) Glutamine reduces heat shockinduced cell death in rat intestinal epithelial cells. $J$ Nutr 128, 1296-1301.

5. Singleton KD \& Wischmeyer PE (2006) Oral glutamine enhances heat shock protein expression and improves survival following hyperthermia. Shock 25, 295-299.

6. Zuhl MN, Lanphere KR, Kravitz L, et al. (2014) Effects of oral glutamine supplementation on exercise-induced gastrointestinal permeability and tight junction protein expression. J Appl Physiol (1985) 116, 183-191.

7. Evans ME, Jones DP \& Ziegler TR (2003) Glutamine prevents cytokine-induced apoptosis in human colonic epithelial cells. J Nutr 133, 3065-3071.

8. Singleton KD, Beckey VE \& Wischmeyer PE (2005) Glutamine prevents activation of NF-kappaB and stress kinase pathways, attenuates inflammatory cytokine release, and prevents acute respiratory distress syndrome (ARDS) following sepsis. Sbock 24, 583-589.

9. Fan J, Meng Q, Guo G, et al. (2009) Effects of enteral nutrition supplemented with glutamine on intestinal mucosal immunity in burned mice. Nutrition 25, 233-239.

10. Wischmeyer PE (2006) The glutamine story: where are we now? Curr Opin Crit Care 12, 142-148.

11. Gouvea Junior VT, Caporossi C, Salomao AB, et al. (2011) Effect of glutamine on the total antioxidant system of rats subjected to renal ischemia and reperfusion. Acta Cir Bras 26, 445-450

12. dos Santos R, Viana ML, Generoso SV, et al. (2010) Glutamine supplementation decreases intestinal permeability and preserves gut mucosa integrity in an experimental mouse model. JPEN J Parenter Enteral Nutr 34, 408-413.

13. US Armed Forces Health Surveillance Center (2012) Heat injuries, active component, U.S. Armed Forces, 2011. Medical Surveillance Monthly Report 19, 14-16.

14. Schar C \& Jendritzky G (2004) Climate change: hot news from summer 2003. Nature 432, 559-560.

15. Hall DM, Buettner GR, Oberley LW, et al. (2001) Mechanisms of circulatory and intestinal barrier dysfunction during whole body hyperthermia. Am J Physiol Heart Circ Physiol 280, H509-H521.

16. Bouchama A \& Knochel JP (2002) Heat stroke. N Engl J Med 346, 1978-1988.

17. Armstrong LE, Casa DJ, Millard-Stafford M, et al. (2007) American College of Sports Medicine position stand.
Exertional heat illness during training and competition. Med Sci Sports Exerc 39, 556-572.

18. Leon LR \& Helwig BG (2010) Heat stroke: role of the systemic inflammatory response. I Appl Physiol (1985) 109 1980-1988.

19. Lambert GP, Gisolfi CV, Berg DJ, et al. (2002) Selected contribution: hyperthermia-induced intestinal permeability and the role of oxidative and nitrosative stress. J Appl Physiol (1985) 92, 1750-1761.

20. Dokladny K, Moseley PL \& Ma TY (2006) Physiologically relevant increase in temperature causes an increase in intestinal epithelial tight junction permeability. Am J Physiol Gastrointest Liver Physiol 290, G204-G212.

21. Oliver SR, Phillips NA, Novosad VL, et al. (2012) Hyperthermia induces injury to the intestinal mucosa in the mouse: evidence for an oxidative stress mechanism. $A m$ J Physiol Regul Integr Comp Physiol 302, R845-R853.

22. Shapiro Y, Alkan M, Epstein Y, et al. (1986) Increase in rat intestinal permeability to endotoxin during hyperthermia Eur J Appl Physiol Occup Physiol 55, 410-412.

23. Gathiram P, Wells MT, Raidoo D, et al. (1988) Portal and systemic plasma lipopolysaccharide concentrations in heatstressed primates. Circ Shock 25, 223-230.

24. Lenhardt R (2010) The effect of anesthesia on body temperature control. Front Biosci (Schol Ed) 2, 1145-1154.

25. Singleton KD \& Wischmeyer PE (2007) Glutamine's protection against sepsis and lung injury is dependent on heat shock protein 70 expression. Am J Physiol Regul Integr Comp Physiol 292, R1839-R1845.

26. Cruzat VF, Rogero MM \& Tirapegui J (2010) Effects of supplementation with free glutamine and the dipeptide alanyl-glutamine on parameters of muscle damage and inflammation in rats submitted to prolonged exercise. Cell Biochem Funct 28, 24-30.

27. Romanovsky AA, Almeida MC, Aronoff DM, et al. (2005) Fever and hypothermia in systemic inflammation: recent discoveries and revisions. Front Biosci 10, 2193-2216.

28. Reeves PG, Nielsen FH, Fahey GC, et al. (1993) AIN-93 purified diets for laboratory rodents: final report of the American Institute of Nutrition ad boc writing committee on the reformulation of the AIN-76A rodent diet. J Nutr 123, 1939-1951.

29. de Oliveira MA, Lemos DS, Diniz SO, et al. (2006) Prevention of bacterial translocation using glutamine: a new strategy of investigation. Nutrition 22, 419-424.

30. Santos RG, Quirino IE, Viana ML, et al. (2014) Effects of nitric oxide synthase inhibition on glutamine action in a bacterial translocation model. Br J Nutr 111, 93-100.

31. Costa KA, Soares AD, Wanner SP, et al. (2014) L-Arginine supplementation prevents increases in intestinal permeability and bacterial translocation in male Swiss mice subjected to physical exercise under environmental heat stress. J Nutr 144, 218-223.

32. Wanner SP, Costa KA, Soares AD, et al. (2014) Physical exercise-induced changes in the core body temperature of mice depend more on ambient temperature than on exercise protocol or intensity. Int J Biometeorol 58, 1077-1085.

33. Lima MR, Pires W, Fonseca IA, et al. (2013) Chronic sympathectomy of the caudal artery delays cutaneous heat loss during passive heating. Neurosci Lett 537, 11-16.

34. Leon LR, Gordon CJ, Helwig BG, et al. (2010) Thermoregulatory, behavioral, and metabolic responses to heatstroke in a conscious mouse model. Am J Physiol Regul Integr Comp Physiol 299, R241-R248.

35. Leon LR, DuBose DA \& Mason CW (2005) Heat stress induces a biphasic thermoregulatory response in mice. $\mathrm{Am}$ J Physiol Regul Integr Comp Physiol 288, R197-R204. 
36. Jorgensen VL, Nielsen SL, Espersen K, et al. (2006) Increased colorectal permeability in patients with severe sepsis and septic shock. Intensive Care Med 32, 1790-1796.

37. Viana ML, Santos RG, Generoso SV, et al. (2010) Pretreatment with arginine preserves intestinal barrier integrity and reduces bacterial translocation in mice. Nutrition $\mathbf{2 6}$, $218-223$.

38. Generoso SV, Viana ML, Santos RG, et al. (2011) Protection against increased intestinal permeability and bacterial translocation induced by intestinal obstruction in mice treated with viable and heat-killed Saccharomyces boulardii. Eur J Nutr 50, 261-269.

39. Batista MA, Nicoli JR, Martins Fdos S, et al. (2012) Pretreatment with citrulline improves gut barrier after intestinal obstruction in mice. JPEN J Parenter Enteral Nutr 36, 69-76.

40. Quirino IE, Cardoso VN, Santos R, et al. (2013) The role of $\mathrm{L}$-arginine and inducible nitric oxide synthase in intestinal permeability and bacterial translocation. JPEN J Parenter Enteral Nutr 37, 392-400.

41. Diniz SO, Resende BM, Nunan EA, et al. (1999) ${ }^{99 \mathrm{~m}}$ Technetium labelled Escherichia coli. Appl Radiat Isot 51, 33-36.

42. Martins FS, Silva AA, Vieira AT, et al. (2009) Comparative study of Bifidobacterium animalis, Escherichia coli, Lactobacillus casei and Saccharomyces boulardii probiotic properties. Arch Microbiol 191, 623-630.

43. Wiest R \& Rath HC (2003) Gastrointestinal disorders of the critically ill. Bacterial translocation in the gut. Best Pract Res Clin Gastroenterol 17, 397-425.

44. Sampaio IBM (2007) Estatística Aplicada à Experimentação Animal (Statistics Applied to Animal Experimentation), 3th ed. Belo Horizonte: Fundacão de Ensino e Pesquisa em Medicina Veterinária e Zootecnia.

45. Bland JM \& Altman DG (2004) The logrank test. BMJ 328, 1073.

46. Choi K, Lee SS, Oh SJ, et al. (2007) The effect of oral glutamine on 5-fluorouracil/leucovorin-induced mucositis/ stomatitis assessed by intestinal permeability test. Clin Nutr 26, $57-62$

47. Welsh FK, Farmery SM, MacLennan K, et al. (1998) Gut barrier function in malnourished patients. Gut 42, 396-401.

48. Yoda T, Crawshaw LI, Yoshida K, et al. (2000) Effects of food deprivation on daily changes in body temperature and behavioral thermoregulation in rats. Am J Physiol Regul Integr Comp Physiol 278, R134-R139.
49. Blikslager AT, Moeser AJ, Gookin JL, et al. (2007) Restoration of barrier function in injured intestinal mucosa. Physiol Rev 87, 545-564.

50. Lebman DA \& Coffman RL (1994) Cytokines in the mucosal immune system. In Handbook of Mucosal Immunology, pp. 243-250 [PL Ogra, J Mestecky, ME Lamm, W Strober, JR McGhee and J Bienenstock, editors]. San Diego, CA: Academic Press.

51. Kiyono H \& McGhee JR (1994) T helper cells for mucosal immune responses. In Handbook of Mucosal Immunology, pp. 263-274 [PL Ogra, J Mestecky, ME Lamm, W Strober, JR McGhee and J Bienenstock, editors]. San Diego, CA: Academic Press.

52. Pearce SC, Mani V, Boddicker RL, et al. (2013) Heat stress reduces intestinal barrier integrity and favors intestinal glucose transport in growing pigs. PLOS ONE 8, e70215.

53. Pearce SC, Mani V, Weber TE, et al. (2013) Heat stress and reduced plane of nutrition decreases intestinal integrity and function in pigs. J Anim Sci 91, 5183-5193.

54. Mainous MR, Tso P, Berg RD, et al. (1991) Studies of the route, magnitude, and time course of bacterial translocation in a model of systemic inflammation. Arch Surg 126, 33-37.

55. Andreasen AS, Pedersen-Skovsgaard T, Mortensen OH, et al. (2009) The effect of glutamine infusion on the inflammatory response and HSP70 during human experimental endotoxaemia. Crit Care 13, R7.

56. Matheson PJ, Harris BT, Hurt RT, et al. (2008) Enteral glutamine supplementation impairs intestinal blood flow in rats. Am J Surg 196, 293-299.

57. Rhoads JM, Argenzio RA, Chen W, et al. (1997) L-Glutamine stimulates intestinal cell proliferation and activates mitogen-activated protein kinases. Am J Physiol 272, G943-G953.

58. Weitzel LR \& Wischmeyer PE (2010) Glutamine in critical illness: the time has come, the time is now. Crit Care Clin 26, 515-525, ix $-x$.

59. Magalhaes FD, Amorim FT, Passos RLF, et al. (2010) Heat and exercise acclimation increases intracellular levels of Hsp72 and inhibits exercise-induced increase in intracellular and plasma Hsp72 in humans. Cell Stress Chaperones 15, $885-895$.

60. Beutheu S, Ouelaa W, Guerin C, et al. (2014) Glutamine supplementation, but not combined glutamine and arginine supplementation, improves gut barrier function during chemotherapy-induced intestinal mucositis in rats. Clin Nutr 33, 694-701. 